\title{
CFD Analysis of Heating Pipe System from Flat Panel Display Devices
}

\author{
Byeong Sam KIM \\ Automotive Engineering Departement \\ Hoseo University \\ Asan City, Korea \\ kbs@hoseo.edu
}

\author{
Kyoungwoo Park \\ Mechanical Engineering Department \\ Hoseo University \\ Asan City, Korea \\ kpark@hoseo.edu
}

\begin{abstract}
This research was conducted on numerical analysis using CFD software in forced vibration analysis of heating pipe under non uniform internal pressure. In order to have competitiveness in the enlarged OLED market, a large display fabrication technology is required. In this paper, a preliminary investigation was carried out for heating pipes using different CFD models available in FLUENT. It sets the calculation model of heat pipe OLED production process according to the characteristics of heat transfer of heat pipe, field distribution inner or outside of pipe reasonably and accurately by FULENT software. It is shown that pressure distribution on the inside of heating pipe caused by inner flow. The vibration analysis using ABAQUS program is employed to demonstrate the characteristic of vibration for each different boundary condition.
\end{abstract}

Keywords - flat panel display; heat pipe; heat treatment process; $C F D$

\section{INTRODUCTION}

The high-integration trend in display production process inevitably has brought the increase of contact or contaminants generated by shock are prevented during panel handling processing substrate. As a contact chuck system composed of several problems in increased potential for fracture or warping. A non contact chuck system is required to solve this problem. The panel warping makes it difficult to carry out conventional fluid problem and vibration problem. Heat flux inside of heat pipe with the OLED panel process using IR type oven flutter caused by the internal fluid flow phenomena and resonance equipment damage that occurs as the stability of the vibration characteristics of structures identified for evaluation is necessary. The OLED production process consisted the IR type oven chamber that the inside heat pipe of hot air is shown in Fig 1.

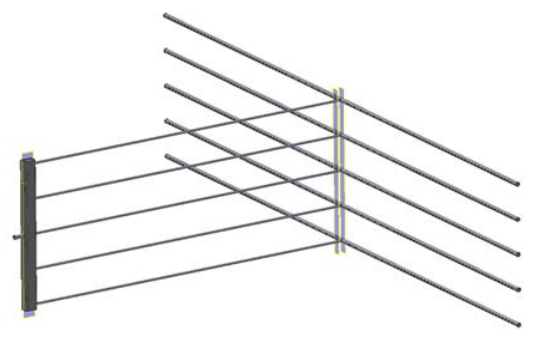

Fig. 1 Structures of heating pipe system
If the fluid flowing inside the pipe, the instability of the structure due to external influences, as well as the influence of the resonance due to the influence of the fluid flow will also occur. The fact that this person through the study of Benjamin, a system which produces unstable flutter critical velocity above suggests that[1] in Fig. 2.

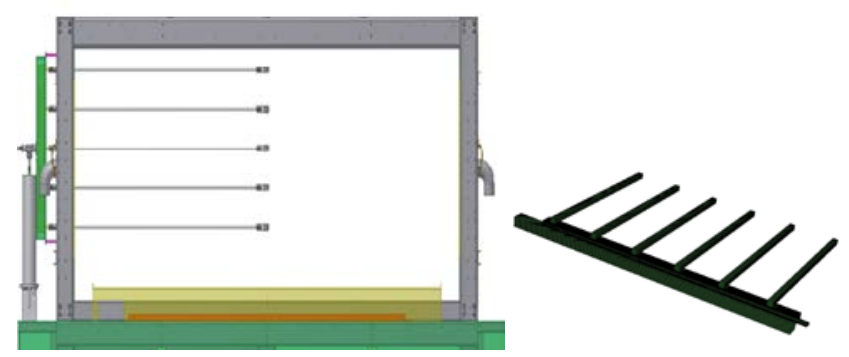

Fig. 2 Heating flow system of OLED production process

Several studies of fluid inside the pipe reaches the threshold if it has one speed, due to the vibration of the pipe buckling instability as well as the structural stability and the fact that the equipment causes performance degradation was observed: [2] In addition, in this paper, extra large OLED Hot air in the interior of IR OVEN process pipe to pipe, as in the case of fluid injection Force focused on the two ends are generated [3].

TABLE 1. ANALYSIS CONDITION OF PIPR IN CASE 1

\begin{tabular}{|c|c|}
\hline Condition & Figure \\
\hline Press & $3500 \mathrm{~Pa}$ \\
\hline Rate of Flow & $400 \mathrm{~L} / \mathrm{min}$ \\
\hline Temperature & $250^{\circ} \mathrm{C}$ \\
\hline
\end{tabular}

TABLE 2.. $\quad$ MATERIAL PROPERTY OF SUS316

\begin{tabular}{|l|l|}
\hline Property & Material Property \\
\hline Density & $8.8 \times 10^{-9}$ tonne $/ \mathrm{mm}^{3}$ \\
\hline
\end{tabular}




\begin{tabular}{|c|c|}
\hline Modulus of Elasticity & $193 \mathrm{Gpa}$ \\
\hline Yield Stress & $241 \mathrm{Mpa}$ \\
\hline Poisson's Ratio & 0.27 \\
\hline
\end{tabular}

The heat pipe air flow of the vibration analysis was used for case 2 and Fig. 3 as a constraint was applied to the other three cases.

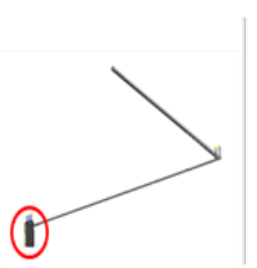

Case 1

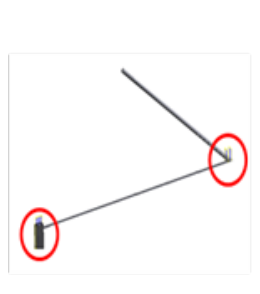

Case 2

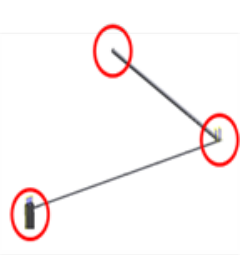

Case 3
Fig. 3 Vibration analysis for boundary condition of each case

Equal to 1 for ease of interpretation and is divided into two case analysis was conducted. Both two kinds of case 1 and 2 only modeled fluid analysis was applied to the Air. Mesh operations using Hyper mesh 11.0 Pyramid mesh was used was analyzed using Fluent 6.1. Analysis of case 1 in Table 1 is the same as the conditions of case 1 and case 2 analysis were entered into the analysis conditions[4][5].

\section{FEM/CFD ANALYSIS}

\section{A. CFD Analysis}

Firstly, CFD analysis with high flow rates of air turbulence generated in the pipe due to hit the pipe vertically folded outer part of the maximum value of the pressure was confirmed with $0.16 \mathrm{Mpa}$.

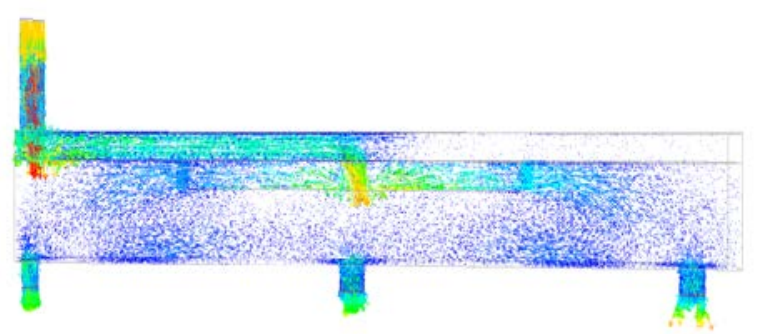

Fig. 4 Analysis of case 1 for heating pipe

Case 1 with five uniform cantilever pipe flowing fluid has a complex shape on the inside of the center of the structure, so as to $1 / 2$ model in Fig. 4. This pipe was treated with symmetry. Case 2, the diameter of $13 \mathrm{~mm}$ and $19.5 \mathrm{~mm} 2$ in the form attached to the vertical one pipe in diameters $19.5 \mathrm{~mm} 2 \sim 7$ $\mathrm{mm}$ in diameter and 45 hole are located. The case 1 analysis of the condition is the same as in Table 2 and hole are located at the surface of the wall boundary layer of the 5 layer standard using the CFD mesh to the inside of the pyramid mesh filled[6]. The case 1 and case 2 is the same as the five pyramid mesh inside the boundary layer after processing conditions were used for analysis of the speed of the simulation results were used case 1 .

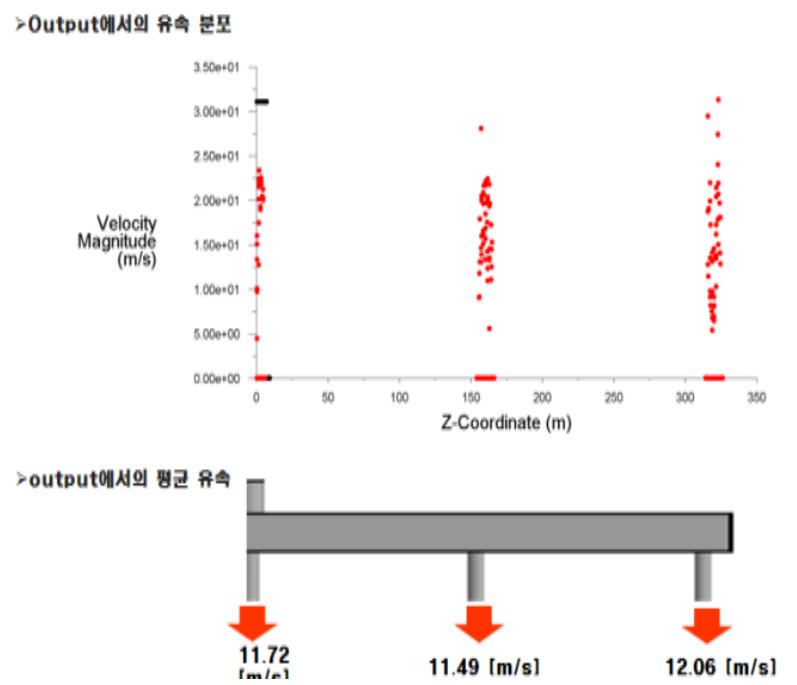

Fig. 5 Exit Velocity of Case 1

\section{B. CFD Results}

The Fig. 5 is shown heat pipe air flow for case 1, the results to determine the flow of air, and Fig. 5 the results obtained from the analysis of each distribution and the average flow velocity at the exit of the shows. Fig 6 . As you can see in the case 2 each with a uniform rate of air was found to be ejected. The heat flow for case 1 and case 2 of the interpretation of the results from the analysis conditions, the maximum flow rate is set to select pipe and pressure distribution on the surface was analyzed.
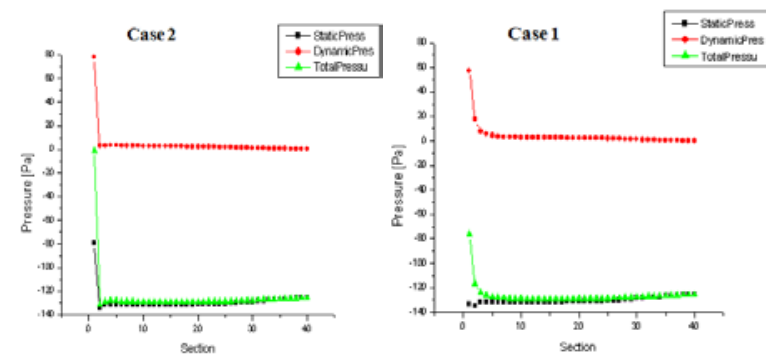

Fig. 6 Pressure distribution

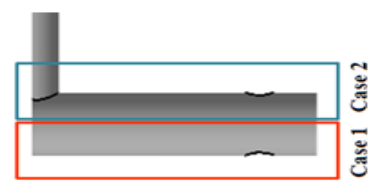

Fig. 7 Heat pipe in each case

The heat pipe in through the exhaust air flow due to the chamber formed inside the pipe due to an internal air flow the pressure is very low compared to the neglected[7]. So pipe the gas if the pressure on the surface of the Bernoulli equation 
derived from equation (1) is defined as:

$$
P_{s}+\frac{1}{2} \rho v^{2}=P_{s}+P_{a}=P_{t}
$$

From equation (1) heat pipe incoming voltage (Pt) by the fluid static pressure (Ps) and dynamic pressure (Pd) is the sum of. Therefore, the voltage of the constant pressure to save the pipe wall (Ps) and dynamic pressure (Pd) and was interpreted as two kinds Fig. 6 and Fig. 7 shows the distribution of the respective pressure. Fig. 8 , analysis of the heat pipe as a result of the constant pressure of air entering the inlet pipe pressure distribution of a large part of the hole escaping to the outside through the air toward the end of the pipe due to the small pressure distribution were able to confirm that[8].

\section{FEM structural analysis}

The structures of heating pipe system for structural analysis using Hyper Works 8.0 design and structural analysis, ABAQUS 6.6-1 simulation was performed using the interpretation model, changing the simulation results and compare the actual results were verified. And the future development of similar systems in the structural analysis obtained by utilizing pre-verified through simulation and performance prediction is to enable. The bake chamber in this study support the slide rail plate frame deflection due to the load and, The chamber frame deflection of the center of the top cover, lift frame deflection due to the weight of the structural analysis and the simulation, the results of the actual equipment compared with the interpretation that the aim was to optimize the model.

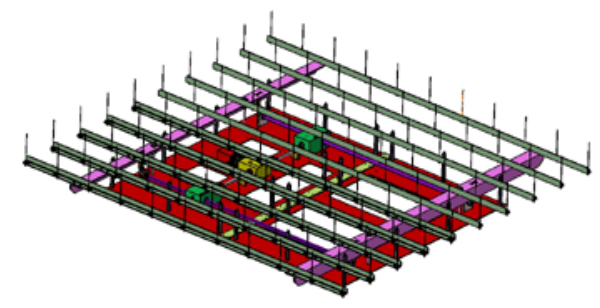

Fig. 8 Structures of heating pipe system

HP Lift Frame material of aluminum is composed of elements of the analysis model was constructed with S4R and C3D8I as shown in Fig. 9. The connections to the lift and frame, frame joint using commercial program ABAQUS the constraint optional redemption feature was only given load weight analysis was performed [9].

TABLE 3. RESULTS OF STRUCTURAL ANALYSIS HP LIFT FRAME

\begin{tabular}{|c|c|c|c|c|}
\hline & Case1 & Case2 & Case3 & Case4 \\
\hline $\begin{array}{c}\text { Displacement } \\
(\mathrm{mm})\end{array}$ & 0.5055 & 0.5356 & 0.4807 & 0.4892 \\
\hline
\end{tabular}

\begin{tabular}{|l|l|l|l|l|}
\hline Stress(MPa) & 4.650 & 3.721 & 5.270 & 4.964 \\
\hline
\end{tabular}

TABLE 4 RESULTS OF STRUCTURAL ANALYSIS BAKE CHAMBER

\begin{tabular}{|c|c|c|c|}
\hline \multirow{2}{*}{} & \multicolumn{2}{|c|}{ Analysis result } & Test result \\
\cline { 2 - 4 } & Max. Stress & Displacement & Displacement \\
\hline HP Lift Frame & $4.650 \mathrm{MPa}$ & $0.5055 \mathrm{~mm}$ & $0.5 \mathrm{~mm}$ \\
$\begin{array}{c}\text { Slide Rail } \\
\text { Plate Frame }\end{array}$ & $176.2 \mathrm{MPa}$ & $10.93 \mathrm{~mm}$ & $10.0 \mathrm{~mm}$ \\
\hline
\end{tabular}

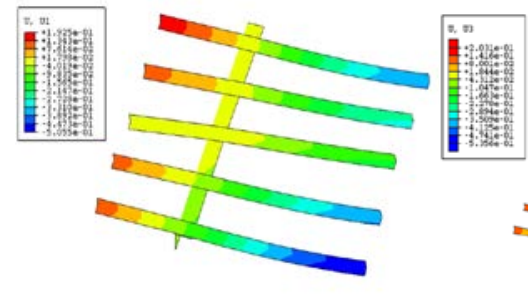

(a) Case 1

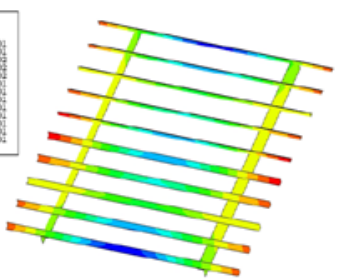

(b) Case 2
Fig. 9 Results of FEM structural analysis in case 1 and case 2 (deforme shape)
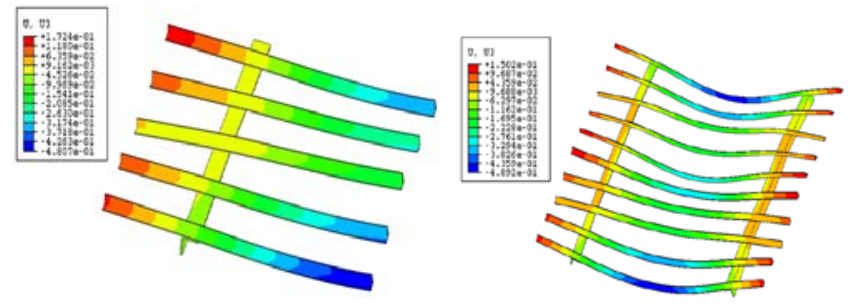

Fig. 10 Results of FEM structural analysis in case 3 and case 4 (deforme shape)

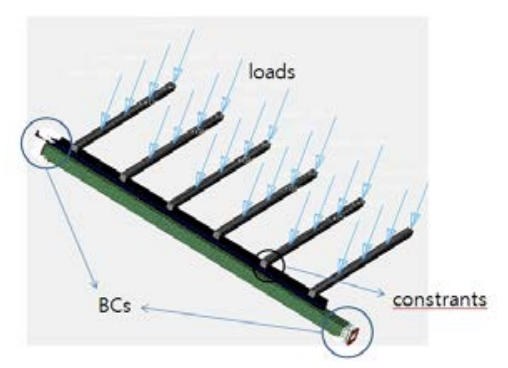

Fig. 11 Constrains condition of Slide rail plate frame

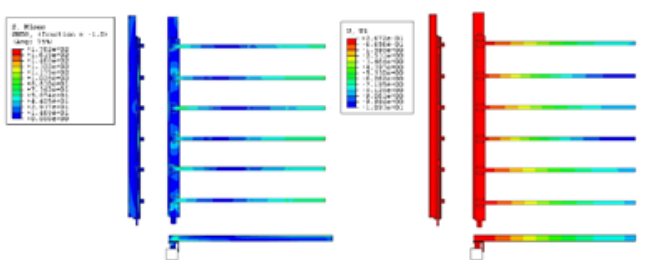


(a) Stress (b) displacement

Fig. 12 Slide rail plate frame analysis result

The bake chamber analysis of the test results and the error range of the analysis results to around $1.0 \mathrm{~mm}$ is considered to be reliable. The frame of bake chamber also receive a relatively low value of the maximum stress for each frame to withstand the load should be enough yen. Fig. 9 and Fig.10 shows the distribution of the stress and displacement. As you can see in the figure, where the stress concentration of plate frame and slide rail plate at the center of the joints and can be seen in Fig. 11. However, the value of the maximum stress to $176 \mathrm{MPa}$ was enough to bear the load of the chamber is evaluated[10]. In addition, Fig.12, the displacement represent the maximum deflection at the center of the plate frame appears to $10.93 \mathrm{~mm}$ in Table 3 and Table 4.

\section{E. Results of FEM structural analysis}

In this paper, through the structural analysis and heat pipe chamber to study the mechanical properties by performing a simulation of the stress distribution and deflection of bake chamber based on data presented. The bake chamber of the three main parts HP lift frame, slide rail plate, frame in the center of the top cover into 3D analysis model was developed, The glass analytical model for the thermal deformation was developed. Based on the analytical model and by performing structural analysis was able to predict the stress distribution and deflection. The analysis and comparison of the test results to verify the analytical results of the analytical model could be optimize.

\section{NVH ANALYSIS}

\section{A. NVH Analysis}

The heat pipe vibration analysis of the constraints applied to the other three cases the analysis was performed for each case, the constraint is shown in Fig 13, heat pipe air flow analysis model analysis of the shape is the same as case 2 model for vibration analysis of pipe material sus316 values required for the analysis are summarized in Table 4. S4R element analysis model was generated by the shell mesh type. The vibration analysis of pipe flow in heat pipe air from the results obtained were interpreted by applying a voltage of pipe. The pressure distribution inside and outside of the bent portion of the pipe consisted, respectively, and each of the 40 quarters. Enter the average value obtained was 8 pressure distribution. Fig. 8 shows a graph of these values[10].

\section{B. NVH Results}
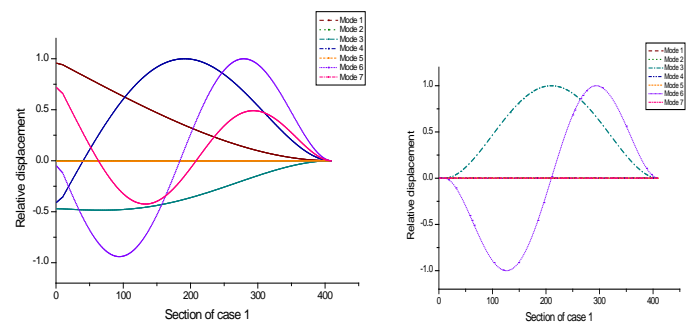

Fig. $13 \mathrm{NVH}$ analysis in each heat pipe (Case 1)

TABLE 5 FREQUENCY OF EACH MODE

\begin{tabular}{|c|c|c|}
\hline $\begin{array}{c}\text { Mode } \\
\text { Number }\end{array}$ & $\begin{array}{c}\text { Frequency } \\
{[\mathrm{Hz}]}\end{array}$ & $\begin{array}{c}\text { Maximum of } \\
\text { Displacement[mm] }\end{array}$ \\
\hline 1 & 1.61 & 36.95 \\
\hline 2 & 9.27 & 77.12 \\
\hline 3 & 13.46 & 71.31 \\
\hline 4 & 21.89 & 68.13 \\
\hline 5 & 56.32 & 77.03 \\
\hline 6 & 63.43 & 67.29 \\
\hline 7 & 80.12 & 67.49 \\
\hline
\end{tabular}

Fig. 14 and Fig. 15, $1 \sim 7$ mode vibration analysis of the results in each case depending on the position of the pipe shows the relative displacement. Increase the number of fixedpoint analysis so as to determine that the frequency of each mode was mode shape of the case 1 , the fixed point 2 when the enemy was in the form of three kinds of case 2, fixed point mode shape increases declined. $1 \sim 7$ mode analysis bending mode in all three cases appear only as torsional mode, radial mode, axial mode, or any other characteristics did not appear.
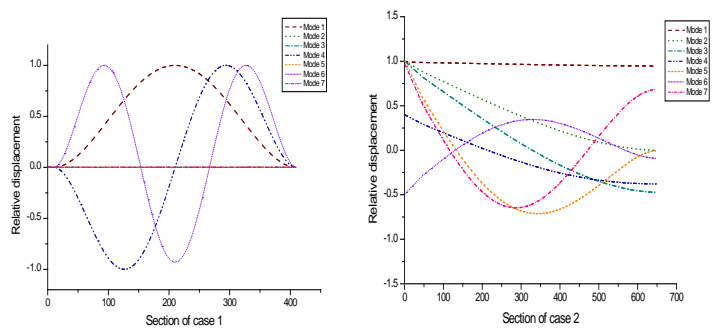

Fig. 14 NVH analysis in each heat pipe (Case 2) 

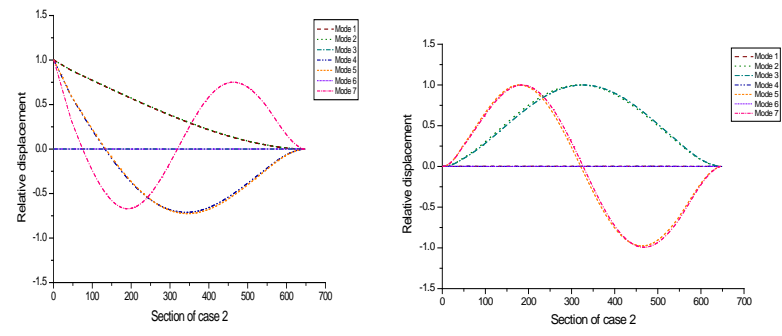

Fig. 15 NVH analysis in each heat pipe (Case 2)

Fig. 14 and Fig. 15, $1 \sim 7$ mode vibration analysis of the results in each case depending on the position of the pipe shows the relative displacement. Increase the number of fixedpoint analysis so as to determine that the frequency of each mode was mode shape of the case 1 , the fixed point 2 when the enemy was in the form of three kinds of case 2, fixed point mode shape increases declined. $1 \sim 7$ mode analysis in all three

cases

bending mode appear only as torsional mode, radial mode, axial mode, or any other characteristics did not appear.

\section{CONCLUSION}

In this paper, through flow analysis and vibration analysis process for super OLED heat pipe air installed inside a computer simulation of the vibration characteristics was performed through suppression. Through this research process super OLED heat pipe air for the internal vibrations of the basic data about the characteristics presented.

Heat pipe air for super OLED process stream flow and the internal distribution of internal pressure, such as pipe was able to predict the natural frequencies and vibration modes could be identified to maximum deflection. Through computer simulations CFD, these super OLED process and vibration analysis for heat pipe air inside the actual production and testing equipment to reduce time and cost, as well as other adjacent or installed inside the machine to avoid resonance due to excitation in the materials will be designed. Fundamental mode frequencies of the largest, most in the loworder due to the presence of mode $1 \sim 7$ for each case was interpreted by the frequency and the maximum deflection is shown in Table 5.

The chamber of the analytical model development and FEM/CFD analysis was create a real need to experiment to reduce the cost and time to be considered. In addition, the interpretation of the analytical model to optimize the time and the results can be predicted more accurately than is believed. This purpose of this study was to develop the analytical model to establish bake chamber through simulation results were used to being able to predict. The structural analysis of the development of technology and design data into a database through the continued development of future large OLED heat chamber be utilized in product development time and costs by shortening the design of economical chamber will make possible.

\section{ACKNOWLEDGMENT}

This research was supported by the Korea Institute for Advancement of Technology(KIAT), Regional industry supporting fund of Chungnam Techno Park in 2013 by grant No. 2012-0438.

\section{REFERENCES}

[1] B.H. Jeon, H.W. Kang and Y. S. Lee, "Free Vibration Characteristics of the Rectangular Plates under Uniform Thermal Loading Part 1. Analytic and FEM analysis”, KSAS journal, vol. 39(2), 2011, pp.97105.

[2] S. Kim, C.X.Cui, M. Y. Park, “Analysis of Natural Frequency of a Wind Turbine Tower-Cable Coupled System”, KSME journal, vol. 39(2), 2011, pp.97-105.

[3] B-S.Kim et al., "A numerical analysis of the dimensional stability of the plastic composites using a thermoviscoelastic composite using a thermoviscoelastic Journal of composite material, vol.36, No.20, pp.2389-2403.

[4] B-S.Kim et al., "Dimensional stability analysis of themoviscoelastic for EMI shielding using Melamine-Formaldehyde composite materials, Int's Conference on Advances in Structural Engineering and Mechanics(ASEM02), 2002.

[5] C. M.Kim. and E.K Kim,. "Ultra-Thinned Si Wafer Processing for Wafer Level 3D Packaging" Journal of KWJS, vol. 26, No. 1,pp12-16. 2008.

[6] A. Syed Nasar, , "Linear electric motors : Theory, Design, and Pratical Applications", Prentice-Hall. Inc. , 1987.

[7] P. C. Sen, "On linear synchronous motor (LSM) for high speed propulsion", IEEE Transaction on Magnetics, vol. Mag-11, No.5, September, pp 1484-1486.

[8] I. H. Moon, S. J.Cho and Y. K. Hwang, "Propulsion Force Coefficient of Injection Nozzle Size on Air Levitation Type Wafer Transfer System", Journal of the Semiconductor \& Display Equipment Technology, Vol. 4, No. 1. pp 35-41. 2005

[9] J-K.Won, J-T.Lee and E-S.Lee, "The Study on the Machining Characteristics of 300mm Wafer Polishing for Optimal Machining Condition" Transactions of the Korean Society of Machine Tool Engineers, Vol.17 No.2 2008.

[10] S-J.Cho, I-H.Moon, D-K.Kim and Y-K.Hwang, "A Study on the Characteristics of Semiconductor Wafer Transportation for Levitation System" Journal of SAREK, pp 1149-1154.

[11] I-H.Moon and Y-K.Hwang. "Evaluation of a Wafer Transportation Speed for Propulsion Nozzle Array on Air Levitation System" Journal of Mechanical Science and Technology(KSME Int. J.) Vol. 20, No. 9, pp. 1492-1501

\section{Creative Commons Attribution License 4.0 (Attribution 4.0 International, CC BY 4.0)}

This article is published under the terms of the Creative Commons Attribution License 4.0 https://creativecommons.org/licenses/by/4.0/deed.en_US 